\title{
High-Performance Concretes Intended for Deep Foundations of Constructions
}

\author{
Martin Tazky ${ }^{*}$, Rudolf Hela \\ Faculty of Civil Engineering, Brno University of Technology, Czech Republic \\ Received November 25, 2019; Revised January 28, 2020; Accepted February 7, 2020
}

Copyright $\odot 2020$ by authors, all rights reserved. Authors agree that this article remains permanently open access under the terms of the Creative Commons Attribution License 4.0 International License

\begin{abstract}
The term high-performance concrete (HPC) can be used to classify any concrete mixture that possesses some added value. One such category of concrete is concrete mixtures used in pile foundation, which must only allow a low degree of water separation (bleeding). The basic components of production of these concretes with high utility properties include the usability of active and passive admixtures and their mutual combinations. As part of this research, analysis of aspects affecting water separation from fresh concrete mixture, including dosing, and the type of individual raw materials, was performed. This article aims to utilise these results to analyse the impact of individual components and to provide a comprehensive theory for how to optimise the design of low-bleeding HPC based on the appropriate selection and mixing ratio of cement and admixture. A set of different raw materials and the effect of their mutual mixing ratios on bleeding and other mechanical and physical parameters of produced mixtures were verified. The results of this experiment demonstrate the clear relationship between the amount of binders up to size $0.25 \mathrm{~mm}$ and amount of water that separates under pressure. Very important aspect is morphology of grains used binders. These knowledge of realized experiment could be easily applied into the practise, same as designed methodology of usage combination of active and passive admixtures to create a maximum cement matrix compaction.
\end{abstract}

Keywords High-Performance Concrete, Deep Foundation, Bleeding, Packing

\section{Introduction}

Modern foundations of constructions, especially large industrial and engineering structures, are based on deep pile foundation technology. The principle of this method of building foundations is based upon the creation of supports abutting their ends to the bearable subsoil. Bored piles are most often used as supports. The length of such a pile depends directly on the depth of the bearable subsoil from the working joint, i.e. from the pile head, which further bears the load of other parts of the construction. This principle of deep foundation is shown in Figure 1.

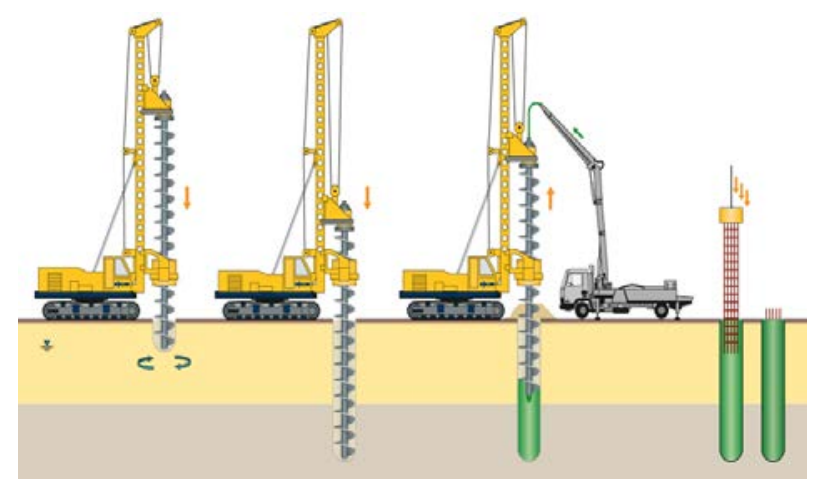

Figure 1. Scheme of production of bored deep piles

Concretes for pile production are divided into two categories according to the requirements of EN 206+A1. These are generally concretes intended for foundations used in dry and wet environments [1]. One of the greatest risks in terms of production and placement of concrete mixture during pile production is its segregation. Concrete used in pile production is generally required to have a high degree of consistency, which, in conjunction with the pressure caused by the weight of the concrete mixture in cases of long pile length, can cause segregation and increased separation of water from the concrete. This water separation is manifested by its ascension to the pile head surface and, in extreme cases, the whole concrete mixture stored in the pile can be degraded.

In terms of the durability of concretes used in pile foundations, there is often an increased demand for an XA environment, meaning an environment in which there is an occurrence of chemical substances. This chemical aggressiveness typically originates from groundwater. 
However, there are certain exceptions such as when sulphate resistant cement is used. The design of concretes with increased resistance to aggressive environments must also respect the requirement for high resistance to water penetration into the internal structure of the composite. The described property can generally be referred to as the water-impermeability of concrete and testing of this aspect is based on standardised procedures.

All the properties of concrete described above, including a high degree of consistency, high resistance to water separation and a high degree of watertightness, can be positively influenced by the use of different types of active or passive admixtures. The correct use of admixtures in the production of high-performance concretes may be the only way to achieve these special properties that are required of the concrete mixtures.

\subsection{Design of Concretes for Pile Foundation}

The design of concretes intended for pile foundation must respect some special requirements resulting from the aggressiveness of the environment and the method of production of deep foundation and it must meet the requirements of the relevant standards. The basic concrete standard EN 206+A1 prescribes the minimum strength class and the minimum content of fine components in concrete for pile foundation. This standard also differentiates between dry and wet storage requirements. The requirements for the minimum content of fine components are based on the theory that a denser structure of cement composite is produced when higher doses of fine components are used.

According to the relevant standards, basic mechanical parameters such as compressive strength and other parameters directly related to the durability of the concrete composite must be verified in pile foundation concretes. These properties include water absorption and depth of pressure water leakage. In terms of fresh concrete mixture, in addition to the consistency that most often achieves the degree of cone slump S3 to S4 according to EN 12350-2 [2], these properties enable the determination of levels of water separation. There are a number of guidance documents for the determination of this parameter of a fresh concrete mixture, which often produce different results. No standardised procedure for this test has been issued in the Czech Republic. The most frequently used procedure is based on the Austrian directive ÖBV - Merkblatt 'Weiche Betone' [3]. The test procedure detailed by this directive is based on the determination of the amount of water pushed out from the fresh concrete mixture at the specified pressure.

Inappropriate designs of concrete intended for pile foundation that do not respect the requirement for a high degree of resistance to water bleeding and segregation can lead to irresolvable failures, which can have a negative impact, not only on the durability of the resulting pile, but also on its static load bearing capacity.
According to the standard provided by EN 206+A1, passive and active admixtures can be used for concretes for pile foundation. The use of these admixtures has several positive effects in terms of economic savings, but also, more crucially, in terms of increasing the ratio of fine components used in the concrete mixture, which has a positive effect on the stability of the mixture.

\subsubsection{Pile Failures and the Use of Admixtures}

The most frequent failures of pile foundations caused by issues with concrete mixtures are increased bleeding and segregation. If the concrete mixture shows an increased tendency to bleed, it may cause significant failures in a pile foundation. A large dose of fresh concrete mixture set in a relatively narrow profile (diameter) with a large height is used for the production of a deep pile. As a result, high pressure stresses arising from the gravity load of the mixture itself are developed and this pressure stress has a major effect on the movement of water towards the top of the pile. The subsequent deterioration of the upper part of a pile caused by excessive bleeding can be seen in Figure 2 [4].

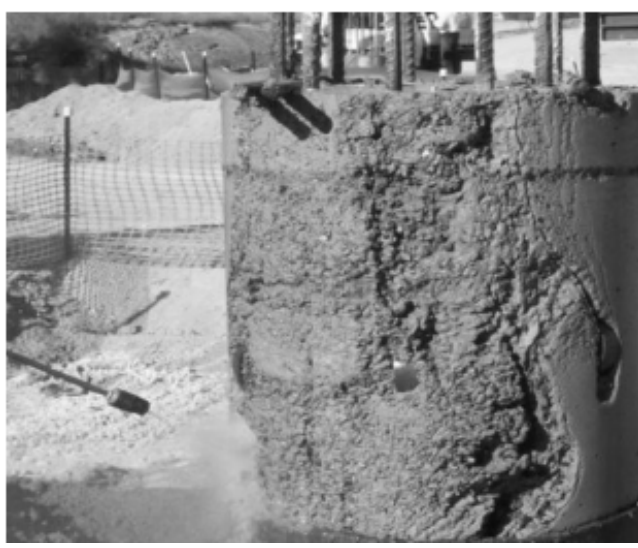

Figure 2. The upper part of the pile damaged by excessive bleeding

In extreme cases, a strong aggregate segregation of the concrete mixture may occur as a result of the movement of cement milk to the upper part of the pile. These failures have a significant impact on the durability of the concrete composite and, in extreme cases, lead to the loss of the pile's static function.

According to the results of several pieces of research and general theories, the resistance of a concrete mixture to bleeding can be positively influenced by the use of an increased dose of fine particles, usually measuring between $0.125 \mathrm{~mm}$ and $0.250 \mathrm{~mm}$. Given this increased dose can only be achieved with certain amounts of cement, this method would be very uneconomical and environmentally unsuitable. It is, therefore, generally recommended to use the content of fine aggregate particles or admixtures in the production of such concrete. Suitable types of admixtures include those with a higher specific surface. In general, both active and passive admixtures can be used.

The general purpose of the use of active or passive 
admixtures is to increase the dose of fine components in the concrete mixture in order to have a positive effect on the resistance to bleeding. In terms of durability, its use is a prerequisite for creating a dense microstructure with high resistance to penetration of aggressive media. With regards to the formation of neoplasms similar to cement hydration products, active admixtures can help to create the maximum density microstructure. However, some studies have considered the suitability of optimal dosing of admixtures in terms of the density of binder mixtures in a dry state. This approach, which can generally be referred to as 'packing', can be used effectively when combining different types of admixtures. Their mutually optimal combination, in terms of the maximum density of a mixture in a dry state, can significantly contribute to the density of the whole concrete matrix [5], [6]. The concept of packing can be seen in Figure. 3.

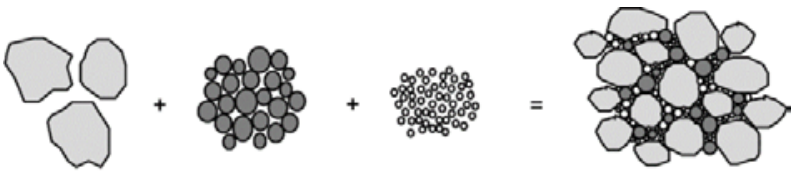

Figure 3. The concept of 'packing'

\section{Methods and Results}

Six concrete mixtures were designed during our experiment. These mixtures differed from each other in the type of admixture used and one sample containing no admixture was used for reference purposes. The design of the concrete mixtures was based on the standards for concrete intended for pile foundations in wet environments.

For all mixtures except the reference mixture, the same grading curve of the aggregate mixture was used, consisting of DTK 0-4mm, HTK 4-8mm, HDK 8-16mm and HDK $11-22 \mathrm{~mm}$. The reference mixture consisted of the same aggregate fractions, but their distribution was different from the distributions of those used in the higher dose $0-4 \mathrm{~mm}$ fraction that substituted the missing fine particles when using admixtures.

The admixture dosing was measured based on the aim of maintaining the same compressive strength after 28 days of normal curing. In tests where combinations of two admixtures were used, their combination was determined using software that calculates the optimum mixing ratio based on the grading curves of the individual components. An example of the resulting graph showing the dependence of the individual types of admixtures mixing on the density of this mixture in a dry state is shown in Figure 4. This optimal mixing ratio ensures that the maximum density of the resulting mixture of mixed components in a dry state is achieved, which is an example of packing.

All the concrete mixtures were produced with the S4 consistency using the slump cone method according to EN 12350-2.

The specific composition of all the concrete mixtures is shown in the following Table 1.

Table 1. The composition of designed concrete mixtures

\begin{tabular}{|c|c|c|c|c|c|c|}
\hline & REF & L7 & L9 & FA & FA+L7 & FA+L9 \\
\hline CEM I 42,5 R & 375 & 315 & 315 & 300 & 300 & 300 \\
\hline Limestone No. 7 & - & 120 & - & - & 50 & - \\
\hline Limestone No. 9 & - & - & 120 & - & - & 67 \\
\hline Fly ash & - & - & - & 120 & 70 & 53 \\
\hline DTK 0-4mm & 825 & 745 & 735 & 740 & 745 & 745 \\
\hline HTK 4-8mm & 235 & 235 & 235 & 235 & 235 & 235 \\
\hline HDK 8-16mm & 475 & 475 & 470 & 475 & 475 & 475 \\
\hline HDK 11-22mm & 360 & 360 & 355 & 360 & 360 & 360 \\
\hline Water & 165 & 175 & 175 & 173 & 170 & 175 \\
\hline Superplasticizer. additive & 3.0 & 4.2 & 4.3 & 3.3 & 4.0 & 4.4 \\
\hline
\end{tabular}


Prior to the production of concrete mixtures, their specific surface was determined for all used binder components using an automatic Blaine apparatus. It was hypothesised that this parameter could directly relate to the bleeding value of the produced concrete mixtures. The results are shown in Table 2.

The concrete mixtures produced were subjected to a slump cone test, in accordance with EN 12350-2 [2], five minutes after production and a test to determine water separation of the concrete under pressure based on the Austrian directive ÖBV - Merkblatt 'Weiche Betone' [3]. The bleeding was determined using a $10 \mathrm{~cm}^{3}$ steel vessel under a pressure of 3 bar. The captured water, which was pushed from the concrete mixture by pressure, was measured after 15 and 60 minutes. The test apparatus is shown in Figure 5. This test simulates the pressure generated by the concrete mixture in the pile's own weight after its production.
Table 2. Specific weight and specific surface of the binder components used according to Blaine

\begin{tabular}{|c|c|c|}
\hline & $\begin{array}{c}\text { Specific weight } \\
{\left[\mathrm{g} / \mathrm{cm}^{3}\right]}\end{array}$ & $\begin{array}{c}\text { Specific surface } \\
{\left[\mathrm{cm}^{2} / \mathrm{g}\right]}\end{array}$ \\
\hline CEM I 42,5 R & 3.09 & 4200 \\
\hline Limestone No. 7 & 2.77 & 3120 \\
\hline Limestone No. 9 & 2.75 & 4490 \\
\hline Fly ash & 2.25 & 2900 \\
\hline L 7. + FA & 2.43 & 2980 \\
\hline L 9. + FA & 2.50 & 3650 \\
\hline
\end{tabular}

The photographs show an obvious loss of concrete volume after 60 minutes at a pressure of 3 bar. The resulting values of water separation, together with the consistency of the concrete mixtures and the concrete density of the mixtures in a fresh state according to EN 12350-6 [7] are shown in Table 3.

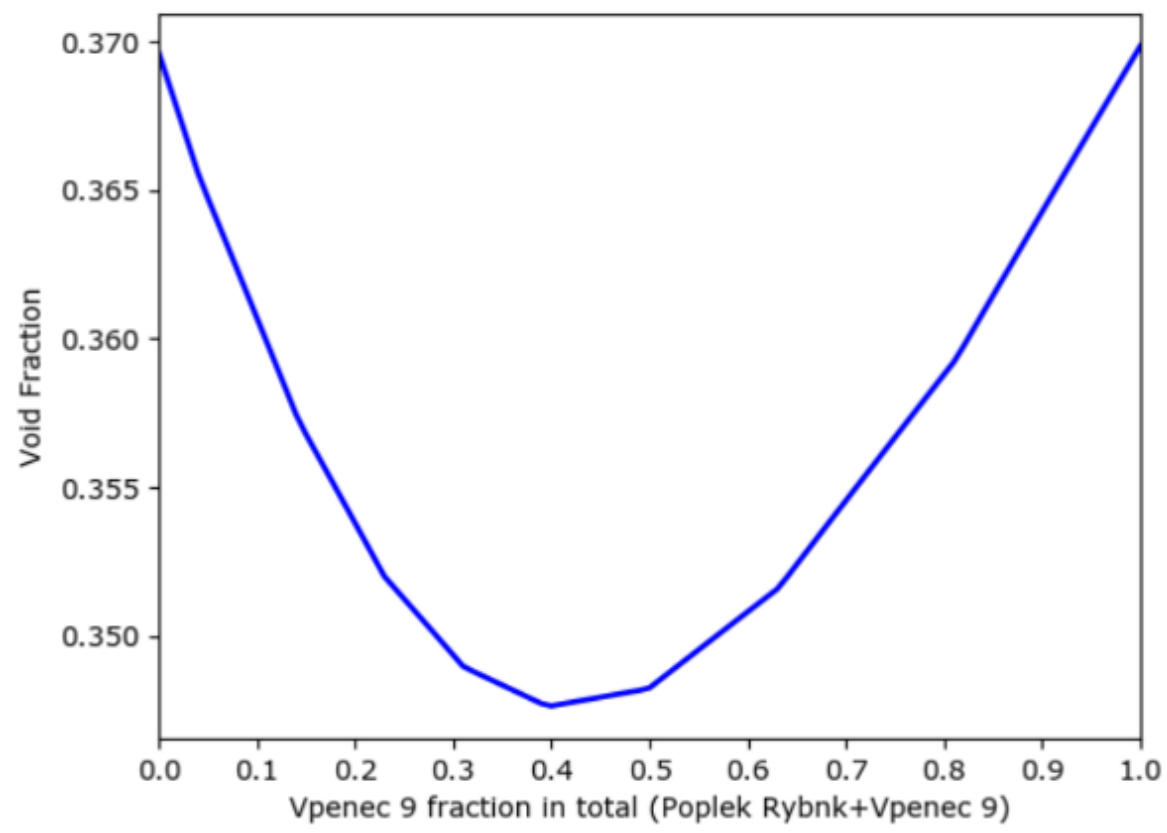

Figure 4. Curve of optimal mixing ratio in terms of density
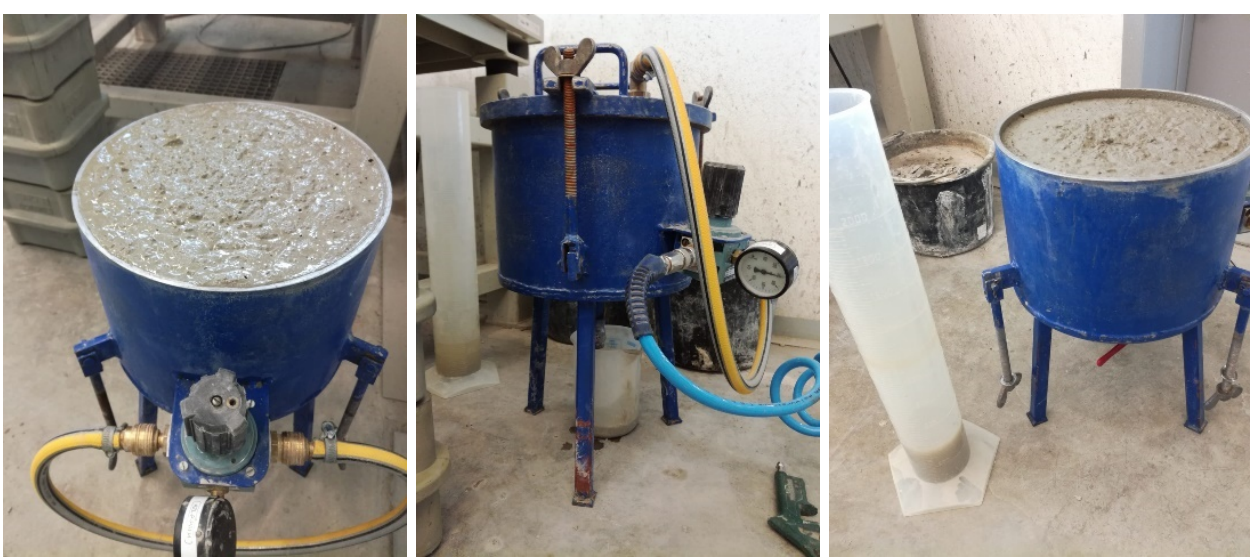

Figure 5. Equipment for determining water separation from concrete according to ÖBV during and after the test 
Table 3. Water separation values of concrete and properties in the fresh state

\begin{tabular}{|l|c|c|c|c|c|c|}
\hline & REF & L7 & L9 & FA & FA+L7 & FA+L9 \\
\hline Water separation after $15 \mathrm{~min}[\mathrm{ml}]$ & 320 & 220 & 188 & 300 & 305 & 300 \\
\hline Water separation after 90 min [ml] & 505 & 375 & 382 & 463 & 475 & 470 \\
\hline Slump after 5 min [mm] & 190 & 190 & 190 & 180 & 180 & 180 \\
\hline Fresh concrete density [kg/m $\left.{ }^{3}\right]$ & 2390 & 2370 & 2370 & 2360 & 2380 & 2390 \\
\hline
\end{tabular}

Table 4. Results of monitored properties of concrete in hardened state

\begin{tabular}{|c|c|c|c|c|c|c|}
\hline & REF & L7 & L9 & FA & FA+L7 & FA+L9 \\
\hline Cured concrete density - after 7 days [kg/m3] & 2400 & 2390 & 2380 & 2350 & 2360 & 2380 \\
\hline Cured concrete density - after 28 days [kg/m3] & 2390 & 2390 & 2380 & 2360 & 2380 & 2400 \\
\hline Cured concrete density - after 90 days [kg/m3] & 2390 & 2390 & 2390 & 2360 & 2390 & 2390 \\
\hline Compressive strength - after 7 days [MPa] & 45.2 & 41.8 & 40.5 & 41.0 & 41.2 & 45.2 \\
\hline Compressive strength - after 28 days [MPa] & 51.1 & 53.4 & 51.9 & 53.3 & 55.2 & 58.0 \\
\hline Compressive strength - after 90 days [MPa] & 51.6 & 57.7 & 53.1 & 68.0 & 64.6 & 64.8 \\
\hline Watertightness HV8 - after 7 days [mm] & 26 & 19 & 20 & 22 & 21 & 25 \\
\hline Watertightness HV8 - after 28 days [mm] & 21 & 15 & 16 & 21 & 16 & 21 \\
\hline Watertightness HV8 - after 90 days [mm] & 20 & 10 & 11 & 8 & 13 & 15 \\
\hline Water absorption - after 7 days [\%] & 6.2 & 5.6 & 6.0 & 6.1 & 6.1 & 5.9 \\
\hline Water absorption - after 28 days [\%] & 5.8 & 5.6 & 5.8 & 6.0 & 5.9 & 5.6 \\
\hline Water absorption - after 90 days [\%] & 5.8 & 5.5 & 5.8 & 5.6 & 5.6 & 6.0 \\
\hline
\end{tabular}

Cube-shaped bodies with a $150 \mathrm{~mm}$ edge were made using the concrete mixtures and these bodies were stored in an aqueous environment at a temperature of $20^{\circ} \mathrm{C}$ throughout the curing period. The compressive strength, according to EN 12390-3 [8]; density of hardened concrete, according to EN 12390-7 [9]; watertightness of hardened concrete, in accordance with TKP ǨVC 1 [10], and water absorption, according to ČSN 731316 [11], were determined on the manufactured bodies after 7, 28 and 90 days. The method for determining the watertightness was chosen in light of the requirement for a higher water pressure to be used in the test than is used for the harmonised standard EN 12390-8 [12]. The test water pressure was $800 \mathrm{kPa}$. All test results are shown in Table 4 .

Figure 6 shows the dependence of the number of fine components up to $0.250 \mathrm{~mm}$ on the bleeding of individual formulas. Also included in this number of fine components are fine components up to the same size originating from aggregates. In order to ensure the thoroughness of the analysis of the impact of the specific surface of the whole system of binder components, such as cement including admixtures, the specific surface, according to Blaine, was determined for this system as well. These results are shown in Table 5. Graphical dependence, as highlighted by Figure 7 , shows the impact of the specific surface of the entire binder mixture on the concrete separation.

Table 5. Specific surface of the binder system according to Blaine

\begin{tabular}{|c|c|}
\hline Formula designation & Specific surface $\left[\mathrm{cm}^{2} / \mathrm{g}\right]$ \\
\hline REF & 4200 \\
\hline L7 & 3840 \\
\hline L9 & 4270 \\
\hline POP & 3830 \\
\hline POP + L7 & 3820 \\
\hline POP + L9 & 4030 \\
\hline
\end{tabular}




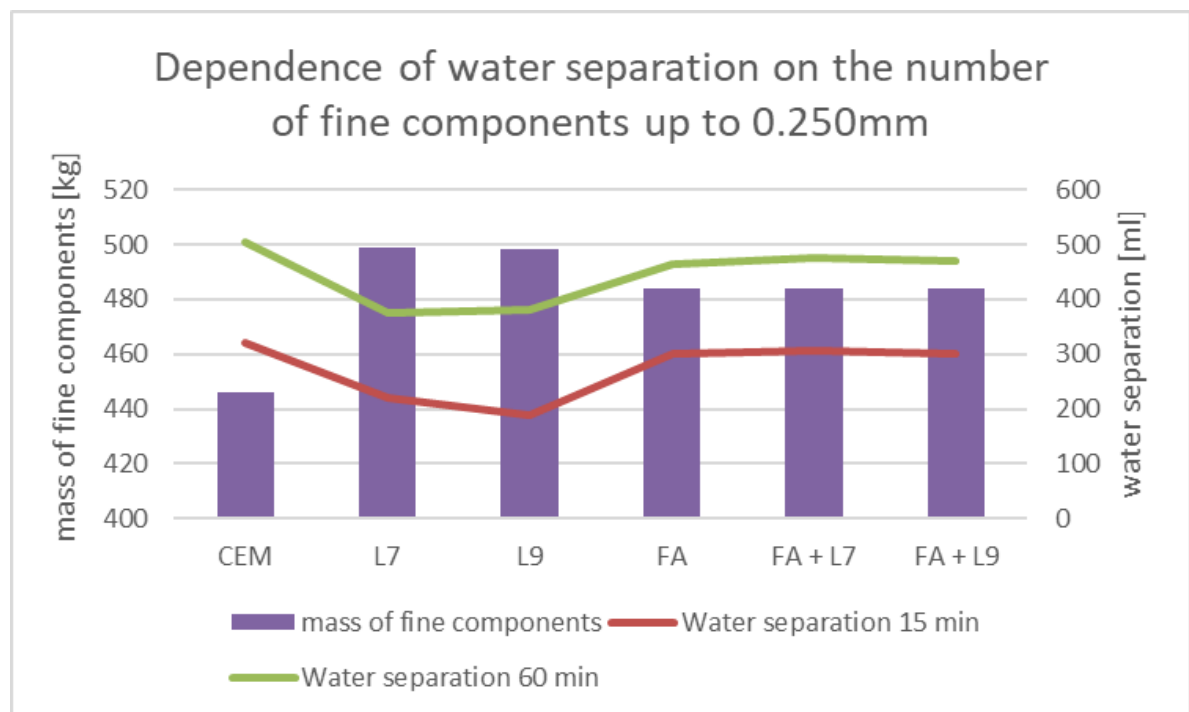

Figure 6. Dependence of water separation on the number of fine components up to $0.250 \mathrm{~mm}$

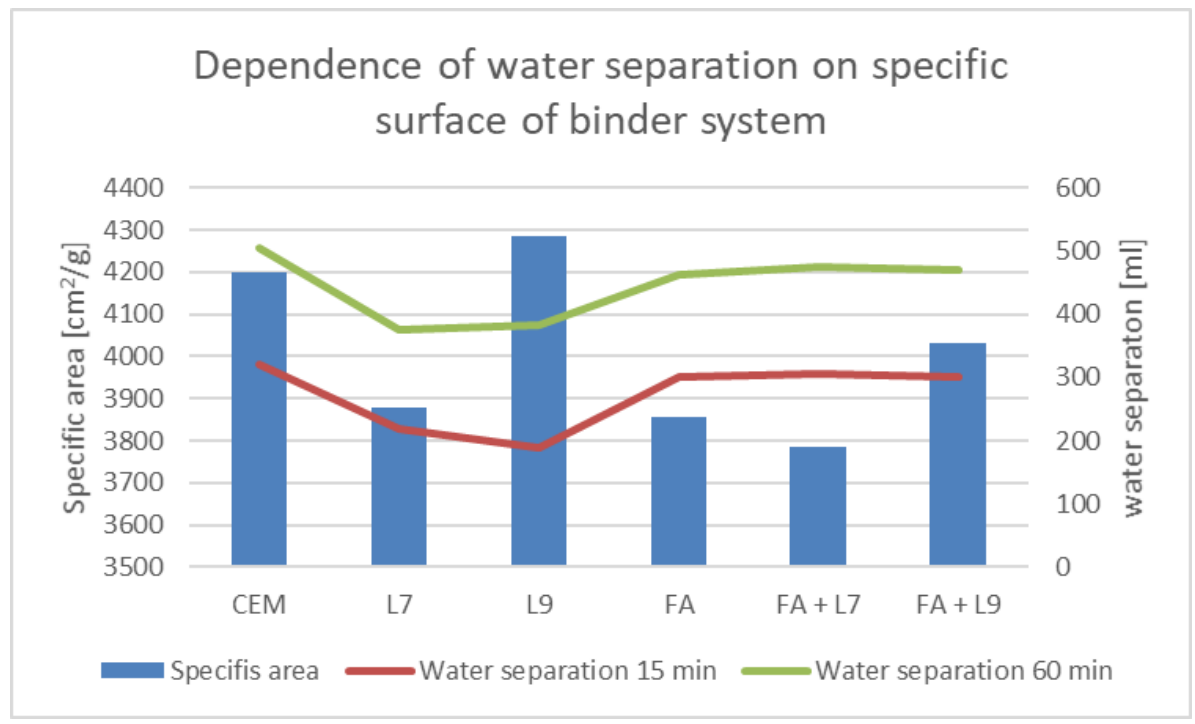

Figure 7. Dependence of water separation on specific surface of binder system

The graphical dependencies and results show considerable differences in water separation of the limestones and fly ash used, although the specific surface of the whole binder mixture does not differ significantly. For this reason, high temperature fly ash and limestone grains were monitored under a scanning electron microscope (SEM). Their morphology was monitored in terms of shape, which could be directly related to water separation itself. Figures 8 and 9 are photos of fly ash and No. 9 limestone grains. 


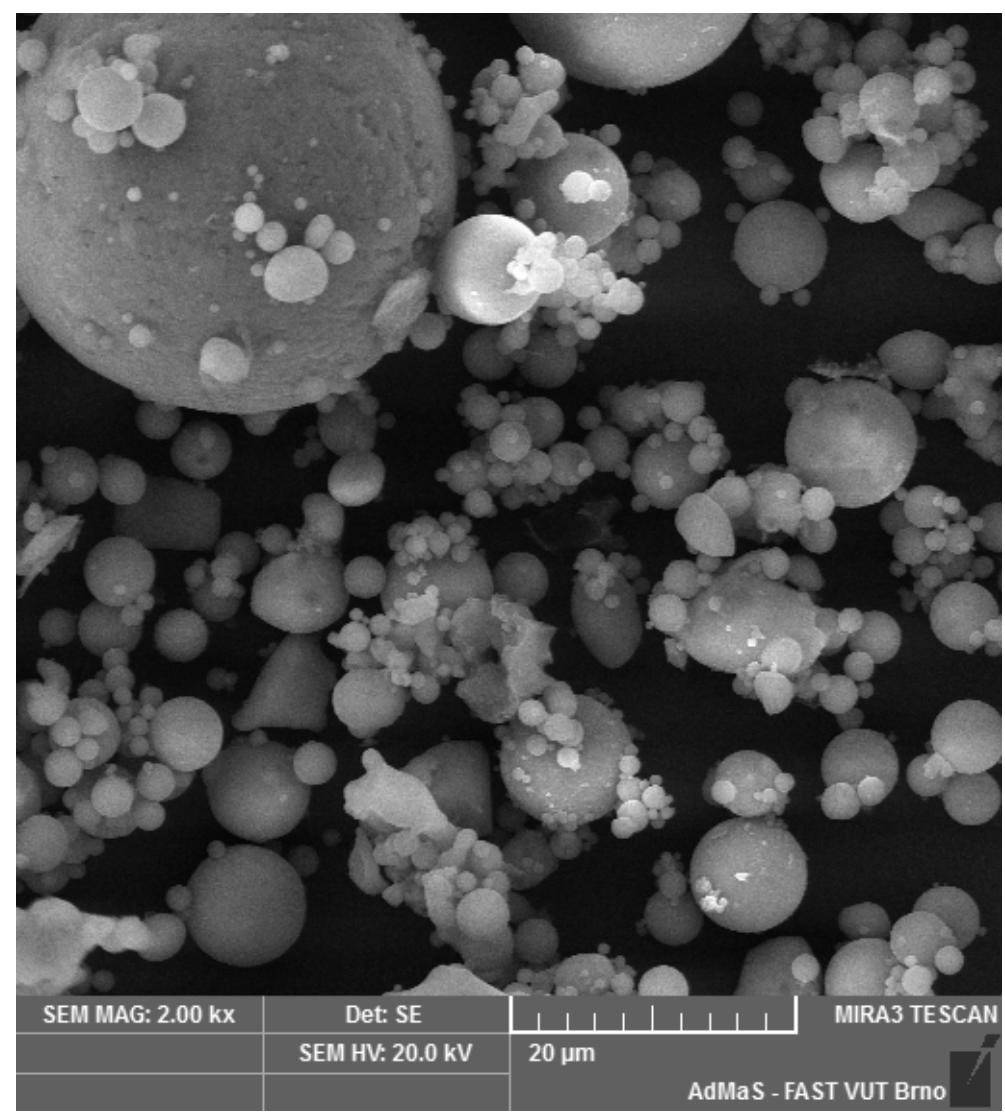

Figure 8. Fly ash grains under SEM - 2000 times magnification

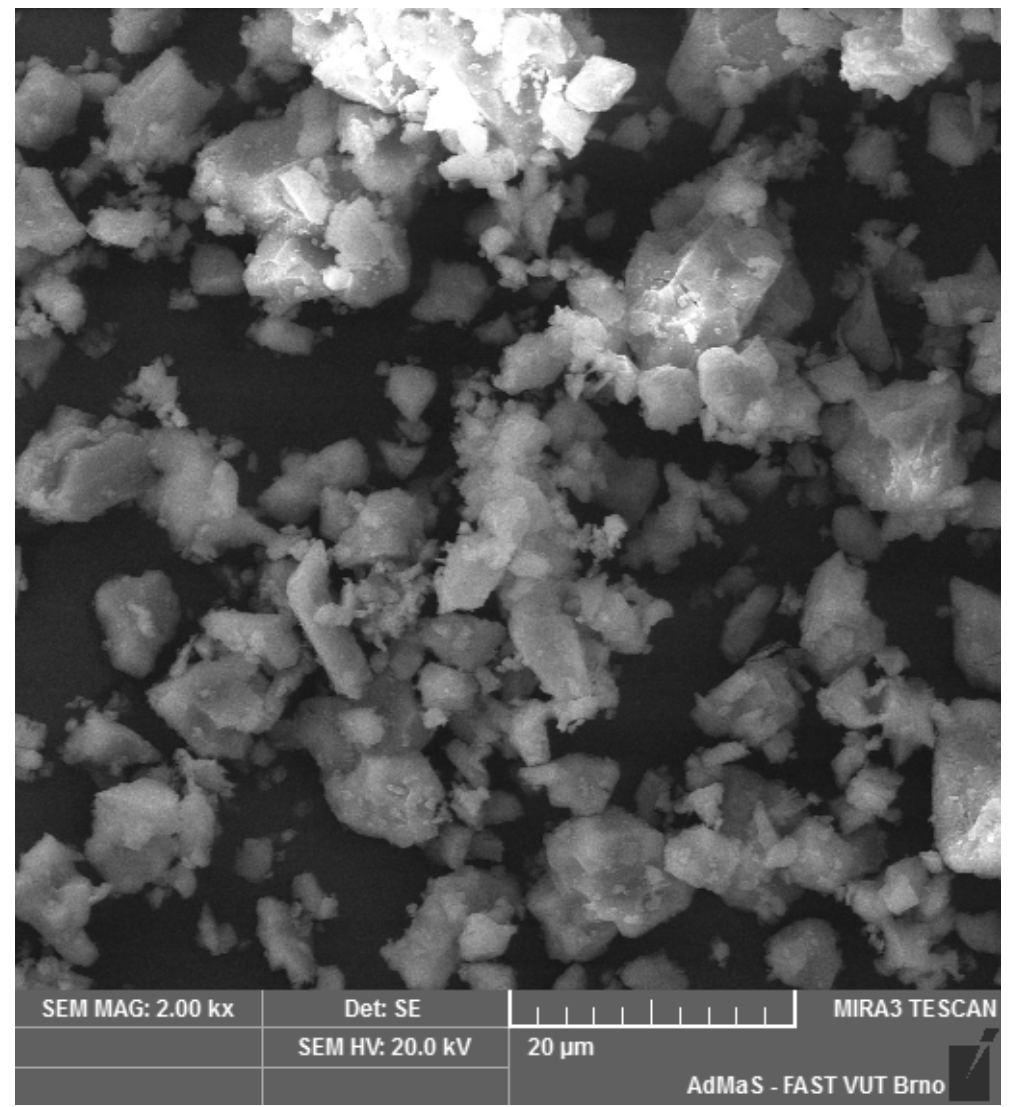

Figure 9. Limestone No. 9 grains under SEM - 2000 times magnification 


\section{Discussion}

The results of the experiment demonstrate the suitability of using admixtures for the production of concrete intended for pile foundations of constructions. In terms of water separation, we can see a direct correlation between the number of fine components in concrete up to the size of $0.250 \mathrm{~mm}$ and the amount of separated water under pressure. With regards to the dependence of water separation on the specific surface of a whole binder system, it is not possible to draw clear conclusions. Of all the admixtures used, high-temperature fly ash appears to be the least suitable. Although the mixtures in which high-temperature fly ash was used show only a slightly lower value for the specific surface of the whole binder system than the formulas using limestone, the water separation of these mixtures is noticeably higher. This probably relates to the grain morphology of the high-temperature fly ash itself, which was monitored under SEM. As expected, the morphology of the grains of high-temperature fly ash and the limestone used was very different. The fly ash grains are predominantly spherical in nature with a glassy surface, which corresponds with widely accepted knowledge of high-temperature fly ash. As a result, it can be assumed that water adhered to a grain surface separates under pressure. From the results of the experiment, very finely grounded No. 9 limestone or recipes made using it seem to be the most suitable materials. This admixture shows the highest value of the specific surface and the grain morphology provides a very heterogeneous impression with the possibility of water absorption on its surface.

However, high-temperature fly ash is an active pozzolanic admixture, which is commonly used to improve the rheological behaviour of a concrete mixture and the quality of cement stone in the long term due to the formation of CSH gels. This experiment demonstrated that this pozzolanic property can be seen as a factor in the highest increase in compressive strength between 7 and 90 days and a decrease in the watertightness value of HV8. High-temperature fly ash is generally one of the most widely used admixtures for the production of these types of concrete for pile foundation.

In terms of strength parameters and watertightness of concrete, the use of the packing concept seems to be suitable. In this experiment, the benefits of using the optimal combination of active admixture, in the form of high-temperature fly ash mixed with a passive admixture in the form of limestone filler, were monitored.

Mixtures with optimised admixture dosing have not been shown to have a positive impact on water separation. Water separation occurred at the same levels as when only using high-temperature fly ash. However, the benefit of this method of dosing the admixtures is that it helps achieve better mechanical parameters, in particular, in this experiment, in terms of achieving a higher compressive strength. Mixtures with optimised dosing of admixtures exhibit the highest compressive strength values after 28 days and these strengths exceed those determined for each admixture individually.

Within the development of concretes intended for pile foundations of constructions, it can be said that the most significant factor in the water separation value of the concrete mixture is the type of admixture used. Admixtures showing high specific surface and suitable grain morphology seem to be most suitable. However, it is necessary to find a suitable boundary between the specific surface value of the binder components and the necessary dose of water to achieve the desired degree of consistency. In terms of the possible impact on the durability of concrete mixtures, the concept of packing of dosing admixtures appears to be highly beneficial. The use of a denser microstructure of cement matrix results in better mechanical parameters of the concrete and the density of the microstructure is expected to have a direct impact on the penetration resistance of aggressive media [13].

\section{Conclusions}

The results of this experiment demonstrate the suitability of using admixtures for the production of concretes intended for pile foundations of constructions. In terms of water separation, there is a clear relationship between the specific surface of a binder system and the amount of water that separates under pressure. However, the most important parameters affecting separation of water from concrete include the morphology of the admixtures used.

It is necessary to pay particular attention to the production of high-quality concretes intended for pile foundations of constructions, particularly in terms of possible bleeding and segregation. Both of these undesirable properties of a fresh concrete mix can cause a significant deterioration in the durability of the concrete pile or a loss of its static function.

The use of admixtures of active or passive types seems to be highly beneficial to the production of these types of concretes. The relationship between the water separation value and the specific surface of an admixture and its grain morphology was monitored. Passive admixtures, in the form of very finely grounded limestone, were recognised in this experiment to be the most suitable. By using the optimum dosage of admixtures according to the packing rule, a higher compressive strength was achieved after 28 days of standard curing compared with the compressive strength of concrete mixtures using individual types of admixture. With regards to the water separation value from concrete, it was not possible to prove the positive effect of using admixtures. 


\section{Acknowledgements}

This paper has been worked out under the project č. FAST-J-19-5944 " Optimization of usability of active and nonactive additives for production of high performance concrete mixtures with low degree of water separation."

\section{REFERENCES}

[1] EN 206+A1. Concrete - Specification, performance, production and conformity, 2018, ÚNMZ, Praha.

[2] EN 12350-2. Testing fresh concrete - Part 2: Slump-test, 2009, ÚNMZ, Praha.

[3] In Austria: ÖBV - Merkblatt "Weiche Betone", 2009.

[4] Beckhaus, K. \& Alehossein, Habib \& Larisch, Martin. New Performance Criteria for fresh Tremie Concrete, 2011.

[5] Dhir, Ravindra \& Mccarthy, M \& Newlands, Moray. Challenges In Designig Concrete Durability, 2019.

[6] Hela, Rudolf \& Tazky, Martin \& Bodnárová, Lenka. Possibilities of determination of optimal dosage of power plant fly ash for concrete. Jurnal Teknologi. 2016.

[7] EN 12350-6. Testing fresh concrete - Part 6: Density, 2009, ÚNMZ, Praha.

[8] EN 12390-3. Testing hardened concrete - Part 3: Compressive strength of test specimens, 2009, ÚNMZ, Praha.

[9] EN 12390-7. Testing hardened concrete - Part 7: Density of hardened concrete, 2019, ÚNMZ, Praha.

[10] In Czech. TKP ŘVC - Kapitola 1: Provádění betonových konstrukcí, 2017, Praha

[11] In Czech: ČSN 73 1316. Stanovení vlhkosti, nasákavosti a vzlnavosti betonu, 1990, ÚNMZ, Praha

[12] EN 12390-8. Testing hardened concrete - Part 8: Depth of penetration of water under pressure, 2019, ÚNMZ, Praha.

[13] Hubacek, Adam \& Hela, Rudolf. Concrete with High Content of Fly Ash Intended for Constructions with Long Durability. Solid State Phenomena. 249. pp. 21-27, 2016 